\title{
Disparities in Learning Mode Access Among K-12 Students During the COVID-19 Pandemic, by Race/Ethnicity, Geography, and Grade Level - United States, September 2020-April 2021
}

Emily Oster, $\mathrm{PhD}^{1,2}$; Rebecca Jack, MPP ${ }^{1}$; Clare Halloran, $\mathrm{PhD}^{1}$; John Schoof ${ }^{1}$; Diana McLeod ${ }^{1,5}$; Haisheng Yang, PhD ${ }^{1,3}$; Julie Roche ${ }^{4}$; Dennis Roche ${ }^{4}$

On June 29, 2021, this report was posted as an MMWR Early Release on the MMWR website (https://www.cdc.gov/mmwr).

In response to the COVID-19 pandemic, schools across the United States began transitioning to virtual learning during spring 2020. However, schools' learning modes varied during the 2020-21 school year across states as schools transitioned at differing times back to in-person learning, in part reflecting updated CDC guidance. Reduced access to in-person learning is associated with poorer learning outcomes and adverse mental health and behavioral effects in children (1-3). Data on the learning modes available in 1,200 U.S. public school districts (representing $46 \%$ of kindergarten through grade 12 [K-12] public school enrollment) from all 50 states and the District of Columbia during September 2020April 2021 were matched with National Center for Education Statistics (NCES) demographic data. Learning mode access was assessed for K-12 students during the COVID-19 pandemic, over time and by student race/ethnicity, geography, and grade level group. Across all assessed racial/ethnic groups, prevalence of virtual-only learning showed more variability during September-December 2020 but declined steadily from January to April 2021. During January-April 2021, access to full-time in-person learning for non-Hispanic White students increased by 36.6 percentage points (from $38.0 \%$ to $74.6 \%$ ), compared with 31.1 percentage points for non-Hispanic Black students (from 32.3\% to 63.4\%), 23.0 percentage points for Hispanic students (from $35.9 \%$ to 58.9\%) and 30.6 percentage points for students of other races/ethnicities (from $26.3 \%$ to $56.9 \%$ ). In January 2021, 39\% of students in grades $\mathrm{K}-5$ had access to full-time in-person learning compared with $33 \%$ of students in grades $6-8$ and $30 \%$ of students in grades 9-12. Disparities in full-time in-person learning by race/ethnicity existed across school levels and by geographic region and state. These disparities underscore the importance of prioritizing equitable access to this learning mode for the 2021-22 school year. To increase equitable access to full-time in-person learning for the 2021-22 school year, school leaders should focus on providing safetyoptimized in-person learning options across grade levels. CDC's $\mathrm{K}-12$ operational strategy presents a pathway for schools to safely provide in-person learning through implementing recommended prevention strategies, increasing vaccination rates for teachers and older students with a focus on vaccine equity, and reducing community transmission (4).
All data for the analyses were publicly available. Data were collected on learning modes used across 1,200 school districts from all 50 states and the District of Columbia, representing $46 \%$ of U.S. K-12 public school enrollment and $90 \%$ of students in the 232 most populous U.S. counties.* Information on learning mode was collected through weekly Internet searches of school district webpages, Facebook, and other public sources for each school district, by grade level group $(\mathrm{K}-5,6-8,9-12)$ or individual grade level, as available, and were classified using the most in-person mode available. ${ }^{\dagger}$ Learning modes were categorized as "full-time in-person" (i.e., access to in-person learning 5 days a week), "virtual-only" (i.e., no access to in-person learning; entirely online, synchronous and asynchronous), or "hybrid" (i.e., access to part-time in-person learning). Data were collected weekly during January-April 2021 and less frequently during September-December 2020 because data collection was not systematized until December 2020.

District enrollment data from the 2019-20 NCES Common Core of Data collected by the U.S. Department of Education (5) were used to estimate enrollment in each of the 1,200 assessed school districts. District and grade-level enrollment data by race/ethnicity from the NCES data were matched to learning mode data to estimate weekly numbers of students with access to each learning mode, by race/ethnicity, geography (state and region), and grade level group. The analytic time frame was September 8, 2020-April 23, 2021. Weekly variation in school learning mode was examined over the 2020-21 school year by race/ethnicity for non-Hispanic White students, non-Hispanic Black students, Hispanic students (of any race), and students of other races/ethnicities $\$$; weekly variation was also assessed by grade level for non-Hispanic White students and students of color. To analyze differences in access to virtual-only, hybrid, and full-time in-person learning modes between non-Hispanic White students and students of color by region** and state, CDC

\footnotetext{
* https://about.burbio.com/methodology/

$\dagger$ For example, districts that offered both full-time in-person and hybrid options to $\mathrm{K}-5$ students are categorized as "full-time in-person for K-5." Grade levels categorized as virtual do not have access to hybrid or full-time in-person learning modes.

$\$$ Other race/ethnicities includes students who identify as American Indian or Alaska Native, Asian or Pacific Islander, or two or more races.

9 "Students of color" includes all students who identify with a race/ethnicity group other than non-Hispanic White.

** Regions of the United States are defined by NCES. https://nces.ed.gov/ nationsreportcard/hsts/tabulations/regions.asp
} 
calculated the mean share of access ${ }^{\dagger \dagger}$ to learning modes over the entire study period. Trends over time for each race/ethnicity group were analyzed using linear regressions of percentage of students with access on number of weeks from the start of the study period with total district enrollment for the race/ethnicity group as analytic weights. To compare regions and states, the mean percentage of students with access and 95\% confidence intervals for the entire study period were calculated using total district enrollment as analytic weights. Stata software (version 16.0; StataCorp) was used to conduct all analyses. This activity was reviewed by CDC and was conducted consistent with applicable federal law and CDC policy. $\$ \$$

Full-time in-person learning access steadily increased starting January 2021 among all assessed racial/ethnic groups $(\mathrm{p}<0.01)$ (Figure 1). During January-April 2021, access to full-time

\footnotetext{
$\dagger_{\dagger}$ To calculate mean difference, the percentage of students with access to virtualonly and full-time in-person learning modes was first calculated for each time point during September 2020-April 2021. The average of these percentages was then calculated over the study period for each learning mode. The percentage point difference of these two means is presented. A positive value indicates a higher percentage of students of color in the learning mode compared with non-Hispanic White students. A negative value indicates a higher percentage of non-Hispanic White students in the learning mode compared with students of color.

$\$ \$ 45$ C.F.R. part 46, 21 C.F.R. part 56; 42 U.S.C. Sect. 241 (d); 5 U.S.C. Sect. 552a; 44 U.S.C. Sect. 3501 et seq.
}

in-person learning for non-Hispanic White students increased by 36.6 percentage points (from $38.0 \%$ to $74.6 \%$ ) compared with 31.1 percentage points for non-Hispanic Black students (from $32.3 \%$ to $63.4 \%$ ), 23.0 percentage points for Hispanic students (from $35.9 \%$ to $58.9 \%$ ), and 30.6 percentage points for students of other races/ethnicities (from $26.3 \%$ to $56.9 \%$ ) (Figure 1). Access to hybrid learning increased by 9.5 percentage points for non-Hispanic White students (from 13.9\% to 23.4\%) compared with 21.7 percentage points for non-Hispanic Black students (from $8.3 \%$ to $30.0 \%$ ), 23 percentage points for Hispanic students (from $9.7 \%$ to $32.7 \%$ ), and 24.6 percentage points for students of other races/ethnicities (from $12.3 \%$ to 36.9\%) (Figure 1). Across all assessed racial/ethnic groups, prevalence of virtual-only learning decreased significantly during September 2020-April 2021 (Figure 1).

During January-April 2021, the percentage of students with access to virtual-only learning decreased by 46.0 percentage points for non-Hispanic White students (48.1\% to 2.1\%), 52.6 percentage points for non-Hispanic Black students $(59.3 \%$ to $6.7 \%), 46.1$ percentage points for Hispanic students $(54.4 \%$ to $8.3 \%$ ), and 55.2 percentage points for students of other races/ethnicities (61.3\% to 6.1\%). During September 2020-April 2021, students in the South had greater

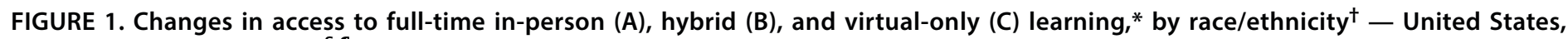
September 2020-April $2021^{\S, 9}$

A. Access to full-time in-person learning

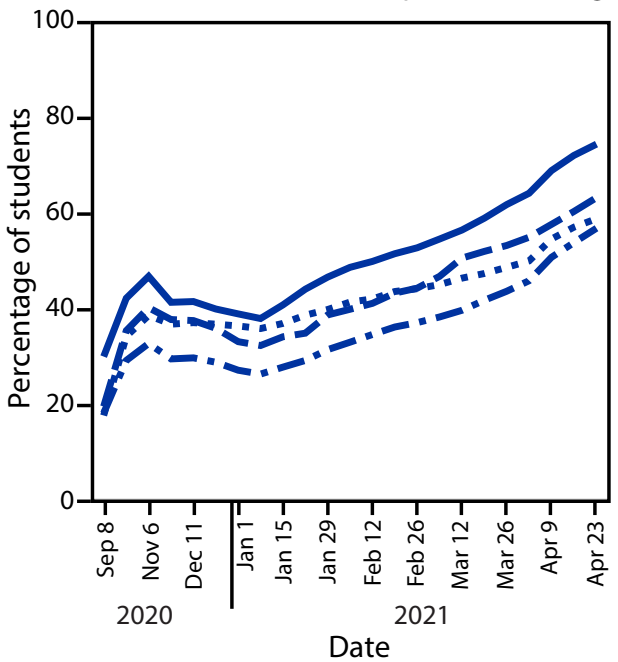

B. Access to hybrid learning

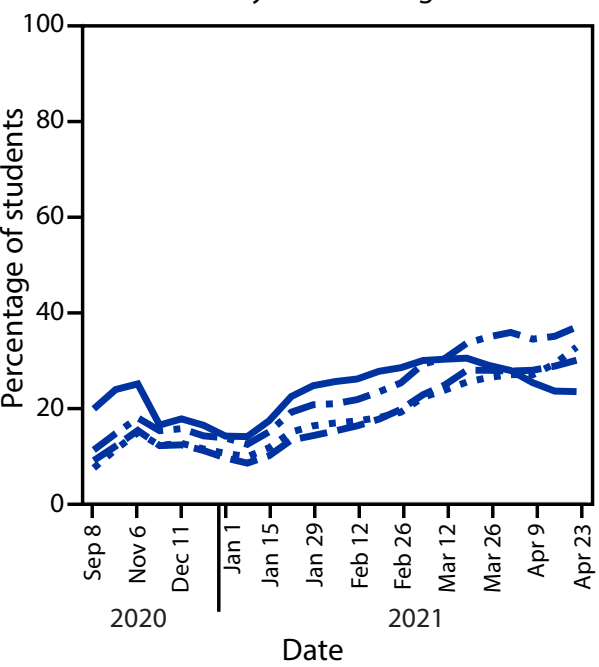

C. Access to virtual-only learning

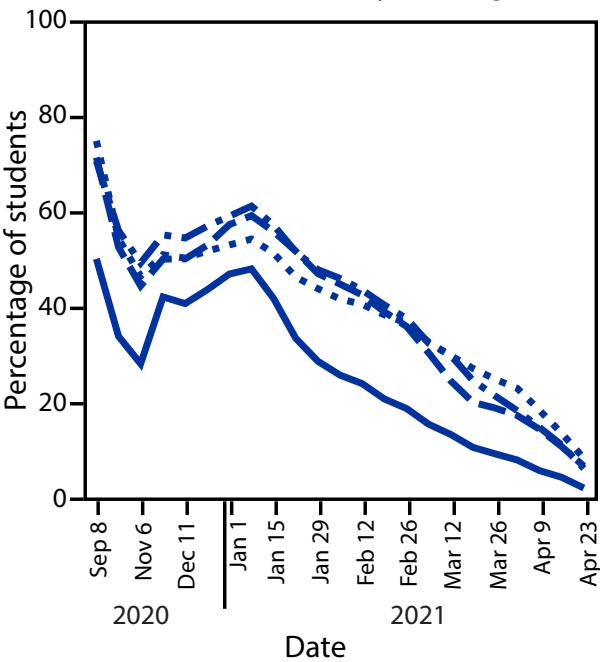

White, non-Hispanic

- Black, non-Hispanic

.. Hispanic

- All other races/ethnicities

* Learning modes are defined as "full-time in-person" (access to in-person learning 5 days a week), "hybrid" (access to part-time in-person learning), and "virtual-only" (no access to in-person learning; entirely online).

† Race/ethnicity data are based on district-level National Center for Education Statistics 2019-20 demographic data (http://nces.ed.gov/ccd/elsi). Hispanic students could be of any race. Students included in "All other races/ethnicities" include non-Hispanic students who are American Indian or Alaska Native, Asian or Pacific Islander, or two or more races.

$\S$ Data before January 1, 2021, were collected less frequently and are not presented at weekly intervals. Data during January 1-April 23, 2021, are presented on a weekly basis. Date labels are condensed for readability.

1" Access to full-time in-person learning increased significantly for all races/ethnicities ( $p<0.01$ for all four regressions), access to hybrid learning increased significantly for all races/ethnicities ( $p<0.01$ for all four regressions), and access to virtual learning decreased significantly for all races/ethnicities ( $p<0.01$ for all four regressions). 
access to full-time in-person learning (62.5\%), on average, compared with other regions (Midwest, 37.1\%; Northeast, $16.2 \%$; and West, $21.8 \%$ ). Access to in-person learning varied by state with the lowest mean percent of all students with access in Hawaii (1.3\%) and highest in Wyoming and Montana (100\%) (Table). In 43 states, access to full-time inperson learning was higher for non-Hispanic White students compared with students of color. The District of Columbia, Delaware, Hawaii, Wyoming, and Montana had the lowest disparity; Ohio and Pennsylvania had the highest.

As of January $8,39 \%$ of $\mathrm{K}-5$ students had access to full-time in-person learning compared with $33 \%$ of students in grades $6-8$ and $30 \%$ of students in grades 9-12; however, differences in full-time in-person learning by race/ethnicity were noted across elementary, middle, and high school levels. During January-April 2021, the difference in access to full-time in-person learning between non-Hispanic White students and students of color in grades $\mathrm{K}-5$ increased by 6.9 percentage points (8.2 percentage points to 15.1 percentage points) compared with increases of 11.4 percentage points at the middle school level (from 2.4 to 13.8) and 12.7 percentage points at the high school level (from 2.1 to 14.8) (Figure 2).

\section{Discussion}

During January-April 2021, overall access to full-time inperson learning increased for all K-12 students. However, disparities in access to full-time in-person learning were apparent by race/ethnicity, geography, and school level. The populations with the most access to full-time in-person learning were non-Hispanic White students, students living in the South, and those in grades K-5. These disparities in learning mode during the COVID-19 pandemic underscore the importance of decreasing community transmission and of increasing equitable access to full-time in-person learning for the 2021-22 school year.

Growing evidence suggests virtual learning can be a challenge for many students, leading to learning losses for children and worsening mental health for children and parents (1-3). Therefore, disparities in access to full-time in-person learning across demographic groups might translate into short-term increases in educational disparities; however, such disparities might be driven by a number of factors (1). For example, urban districts might be less likely to open for full-time in-person learning, in part because of higher COVID-19 community rates, and these districts generally include more students of color (6). Further, rates of COVID-19 hospitalization and mortality have been higher in communities of color, and districts serving a larger share of these students might have faced more significant public health challenges as they made decisions about reopening schools $(7,8)$.

The findings in this report are subject to at least five limitations. First, the study assessed access to different learning modes and not how students actually received instruction. Some evidence suggests that families of color are less likely to opt in to full-time in-person school, even when it is an option, because they are more likely to be concerned about their child contracting COVID-19 and about students not complying with COVID-19 mitigation practices in schools (9). Second, data included in this report cover only 1,200 school districts out of the 13,057 in the nation (5), representing only $46 \%$ of public K-12 enrollment in the United States; therefore, although the sampling frame is more representative of larger districts in more populated areas, it is not representative of the entire United States. Third, data were collected from public sources that could reflect inaccuracies if not updated frequently. Fourth, data were collected less frequently during September-December 2020 because data collection was not systematized until December 2020. Finally, these data do not directly measure changes in learning outcomes; such outcomes might be affected by types of learning modes (1).

This study documents disparate access to full-time in-person learning across racial/ethnic groups among U.S. K-12 students over the 2020-21 school year, by geography and school level. These results highlight the importance of continued efforts to address inequities in access to the full-time in-person learning mode, including increasing vaccination coverage to reduce community transmission in all populations. Evidence suggests that many $\mathrm{K}-12$ schools that have optimized prevention strategies have safely opened for full-time in-person learning and remained open (10). To increase equitable access to fulltime in-person learning for the 2021-22 school year, school leaders should focus on providing safety-optimized in-person learning options across grade levels. CDC's K-12 operational strategy presents a pathway for schools to safely provide inperson learning through implementation of recommended prevention strategies, increasing vaccination rates, and reducing community transmission (4).

Corresponding author: Emily Oster, emily_oster@brown.edu.

${ }^{1}$ COVID-19 School Response Dashboard, Providence, Rhode Island; ${ }^{2}$ Brown University, Providence, Rhode Island; ${ }^{3}$ Abt Associates, Chamblee, Georgia; ${ }^{4}$ Burbio, New York, New York; ${ }^{5}$ Precision Development, Boston, Massachusetts.

All authors have completed and submitted the International Committee of Medical Journal Editors form for disclosure of potential conflicts of interest. No potential conflicts of interest were disclosed. 
TABLE. Mean difference in access* to full-time in-person compared with virtual-only learning modes ${ }^{\dagger}$ between non-Hispanic White students and students of color, $\$$ by region and jurisdiction ${ }^{\natural}$ — United States, September 2020-April 2021

\begin{tabular}{|c|c|c|c|c|c|}
\hline \multirow[b]{2}{*}{ Area } & \multirow[b]{2}{*}{$\begin{array}{c}\text { Total enrollment } \\
\text { included in sample }\end{array}$} & \multicolumn{2}{|c|}{ Full-time in-person access } & \multicolumn{2}{|c|}{ Virtual-only access } \\
\hline & & $\begin{array}{l}\text { Mean percentage of students } \\
\text { with access }(95 \% \mathrm{Cl})\end{array}$ & $\begin{array}{l}\text { Mean difference in access for } \\
\text { students of color }(95 \% \mathrm{CI})\end{array}$ & $\begin{array}{l}\text { Mean percentage of students } \\
\text { with access }(95 \% \mathrm{Cl})\end{array}$ & $\begin{array}{l}\text { Mean difference in access for } \\
\text { students of color }(95 \% \mathrm{Cl})\end{array}$ \\
\hline \multicolumn{6}{|l|}{ Region } \\
\hline South & $11,733,585$ & 62.5 (61.4 to 63.5$)$ & $-3.5(-4.5$ to -2.5$)$ & 21.6 (20.7 to 22.5$)$ & $3.8(2.2$ to 5.5$)$ \\
\hline Midwest & $3,280,369$ & 37.1 (36.1 to 38.1 ) & $-20.1(-21.7$ to -18.4$)$ & 36.7 (35.7 to 37.8 ) & 22.6 (19.3 to 25.9$)$ \\
\hline West & $5,451,104$ & 21.8 (20.8 to 22.7 ) & $-22.6(-24.3$ to -20.9$)$ & $58.4(57.2$ to 59.6$)$ & 26.7 (24.3 to 29.2 ) \\
\hline Northeast & $1,974,998$ & $16.2(15.5$ to 17.0$)$ & $-12.3(-14.8$ to -9.9$)$ & 41.7 (40.6 to 42.8 ) & 31.0 (28.8 to 33.2$)$ \\
\hline \multicolumn{6}{|l|}{ Jurisdiction } \\
\hline Wyoming & 27,751 & $100.0(100.0)$ & $0(-)$ & $0(-)$ & $0(-)$ \\
\hline Montana & 12,488 & $100.0(100.0)$ & $0(-)$ & $0(-)$ & $0(-)$ \\
\hline Florida & $2,679,579$ & 98.4 (97.6 to 99.2 ) & $-1.1(-3.2$ to 1.1$)$ & 1.3 (0.5 to 2.1$)$ & $1.1(-1.1$ to 3.3$)$ \\
\hline Arkansas & 102,025 & 81.5 (75.5 to 87.5$)$ & 21.3 (20.6 to 22.0 ) & $1.0(-0.5$ to 2.5$)$ & $0.4(-0.4$ to 1.1$)$ \\
\hline Utah & 435,494 & 79.5 (74.7 to 84.3$)$ & $-18.9(-21.0$ to -16.9$)$ & 2.7 (0.7 to 4.6$)$ & $3.6(2.1$ to 5.0$)$ \\
\hline South Dakota & 43,311 & 76.8 (66.7 to 86.8$)$ & $-0.8(-1.0$ to -0.6$)$ & $0.0(-)$ & $0(-)$ \\
\hline Texas & $3,054,742$ & 74.8 (73.1 to 76.5$)$ & $-13.5(-15.1$ to -11.9$)$ & 5.8 (4.9 to 6.8 ) & 4.3 (2.1 to 6.4 ) \\
\hline Louisiana & 257,164 & 74.6 (71.0 to 78.1$)$ & $-11.0(-12.5$ to -9.5$)$ & $1.2(-0.3$ to 2.6$)$ & $1.3(-0.4$ to 2.9$)$ \\
\hline Nebraska & 146,720 & 73.6 (68.8 to 78.5$)$ & $-10.6(-17.9$ to -3.3$)$ & 3.8 (1.6 to 5.9$)$ & 3.8 (0.0 to 7.7 ) \\
\hline Alabama & 293,702 & 69.5 (64.3 to 74.6$)$ & $-8.8(-13.2$ to -4.5$)$ & 17.3 (13.1 to 21.5 ) & 14.8 (10.4 to 19.1$)$ \\
\hline Mississippi & 120,489 & 69.2 (63.4 to 75.0$)$ & $-16.3(-22.0$ to -10.7$)$ & 11.2 (6.9 to 15.4 ) & 15.8 (9.1 to 22.5$)$ \\
\hline Georgia & $1,012,693$ & 68.5 (64.5 to 72.6$)$ & $-17.3(-18.0$ to -16.6$)$ & 23.9 (20.1 to 27.6$)$ & 15.1 (12.7 to 17.5$)$ \\
\hline South Carolina & 497,693 & 67.7 (64.3 to 71.1$)$ & $-2.2(-3.1$ to -1.4$)$ & 8.9 (6.4 to 11.3$)$ & 2.8 (0.9 to 4.8 ) \\
\hline North Dakota & 44,341 & 65.8 (57.5 to 74.2 ) & $0.1(-1.1$ to 1.3$)$ & 0.6 (-0.6 to 1.8$)$ & 0.1 (-0.1 to 0.3$)$ \\
\hline Arizona & 348,120 & 64.7 (60.4 to 69.1$)$ & $-14.2(-17.2$ to -11.2$)$ & 25.6 (21.5 to 29.8 ) & 15.6 (11.6 to 19.6$)$ \\
\hline lowa & 124,369 & 60.0 (53.8 to 66.2 ) & $-7.1(-10.3$ to -3.8$)$ & 10.7 (6.9 to 14.6$)$ & 3.7 (0.7 to 6.7) \\
\hline Tennessee & 494,768 & 58.8 (53.2 to 64.3$)$ & $-16.9(-24.7$ to -9.1$)$ & 36.6 (30.9 to 42.2 ) & 21.7 (13.2 to 30.1$)$ \\
\hline Missouri & 271,026 & 55.8 (52.3 to 59.3$)$ & $-14.1(-15.8$ to -12.4$)$ & 21.5 (18.1 to 24.9$)$ & 22.8 (18.6 to 27.0 ) \\
\hline Indiana & 328,466 & 55.1 (52.4 to 57.8 ) & $-14.7(-16.1$ to -13.4$)$ & 16.1 (13.7 to 18.6$)$ & 10.9 (7.1 to 14.8$)$ \\
\hline Oklahoma & 153,078 & 53.7 (48.1 to 59.3 ) & $-20.5(-25.8$ to -15.1$)$ & 26.7 (21.3 to 32.1$)$ & 18.1 (11.4 to 24.8 ) \\
\hline Kansas & 184,604 & 52.9 (48.1 to 57.7$)$ & $-7.4(-10.9$ to -4.0$)$ & 29.3 (23.9 to 34.7 ) & 15.0 (11.6 to 18.3$)$ \\
\hline Idaho & 126,946 & 44.8 (39.4 to 50.2 ) & $-8.4(-10.3$ to -6.5$)$ & 13.2 (8.3 to 18.0 ) & 5.0 (1.7 to 8.3$)$ \\
\hline Colorado & 651,020 & 44.3 (41.5 to 47.2 ) & $-4.6(-6.2$ to -3.0$)$ & 28.7 (25.0 to 32.4 ) & 2.4 (0.0 to 4.9$)$ \\
\hline Vermont & 11,215 & 44.1 (38.1 to 50.2 ) & $-1.5(-4.1$ to 1.0$)$ & 8.5 (4.8 to 12.3 ) & 4.4 (2.1 to 6.7$)$ \\
\hline Michigan & 345,524 & 40.9 (38.5 to 43.2$)$ & $-20.7(-26.8$ to -14.7$)$ & 44.7 (42.2 to 47.2$)$ & 21.6 (15.8 to 27.4$)$ \\
\hline Alaska & 70,370 & 40.1 (31.9 to 48.3 ) & $-1.4(-4.9$ to 2.1$)$ & 41.6 (31.2 to 52.0$)$ & 12.5 (8.9 to 16.1$)$ \\
\hline West Virginia & 56,868 & 39.9 (28.4 to 51.4$)$ & $-0.7(-2.4$ to 0.9$)$ & 28.4 (18.0 to 38.8 ) & $1.2(-0.7$ to 3.0$)$ \\
\hline Ohio & 499,577 & 36.8 (34.5 to 39.2 ) & $-23.2(-25.4$ to -21.0$)$ & 32.1 (29.9 to 34.4 ) & $21.8(16.2$ to 27.4$)$ \\
\hline Connecticut & 143,101 & 35.4 (31.9 to 38.9 ) & $-9.8(-13.4$ to -6.3$)$ & 19.1 (15.8 to 22.4 ) & 9.9 (7.0 to 12.9$)$ \\
\hline Rhode Island & 43,015 & 35.1 (30.9 to 39.3 ) & $3.6(0.8$ to 6.4$)$ & 26.7 (19.6 to 33.8 ) & $-3.3(-8.4$ to 1.8$)$ \\
\hline Minnesota & 227,000 & 30.4 (26.5 to 34.3 ) & $-2.1(-3.6$ to -0.5$)$ & 50.2 (45.4 to 55.0 ) & $11.9(8.6$ to 15.1$)$ \\
\hline North Carolina & 942,072 & 25.5 (23.0 to 28.0 ) & $-4.6(-5.4$ to -3.7$)$ & 38.5 (34.7 to 42.2 ) & 10.9 (7.9 to 13.8$)$ \\
\hline Wisconsin & 268,237 & 25.5 (22.3 to 28.8 ) & $-12.9(-15.7$ to -10.2$)$ & 59.6 (55.5 to 63.7$)$ & 27.3 (22.7 to 31.9 ) \\
\hline Pennsylvania & 633,775 & 22.4 (20.8 to 24.0 ) & $-21.5(-25.6$ to -17.5$)$ & 44.1 (42.1 to 46.2 ) & 38.6 (35.7 to 41.6 ) \\
\hline Kentucky & 199,713 & 17.8 (12.3 to 23.3$)$ & $-9.0(-11.3$ to -6.8$)$ & 63.4 (56.3 to 70.4$)$ & 12.6 (8.4 to 16.7$)$ \\
\hline Delaware & 90,500 & 15.1 (11.7 to 18.6$)$ & $0.0(-1.1$ to 1.0$)$ & 27.1 (21.4 to 32.7 ) & 4.1 (1.9 to 6.3 ) \\
\hline New Mexico & 170,693 & 14.9 (9.5 to 20.2 ) & $-1.2(-1.6$ to -0.7$)$ & 77.2 (71.2 to 83.2 ) & 3.2 (2.0 to 4.3$)$ \\
\hline New Hampshire & 52,543 & 14.8 (10.7 to 18.9$)$ & $-8.5(-11.4$ to -5.5$)$ & 25.8 (20.7 to 30.8$)$ & 10.7 (6.3 to 15.1$)$ \\
\hline Nevada & 408,723 & 13.6 (8.6 to 18.5 ) & $-6.4(-7.3$ to -5.4$)$ & 65.7 (56.4 to 75.1$)$ & 10.8 (8.6 to 12.9 ) \\
\hline New York & 377,921 & 13.5 (12.3 to 14.8$)$ & $-5.7(-7.0$ to -4.4$)$ & 25.1 (23.1 to 27.1 ) & 14.3 (10.9 to 17.7$)$ \\
\hline Virginia & 873,746 & 12.2 (9.9 to 14.5 ) & $-7.1(-8.3$ to -5.9$)$ & 59.2 (55.5 to 62.9 ) & 8.0 (6.8 to 9.1$)$ \\
\hline Illinois & 797,194 & 10.1 (8.7 to 11.6 ) & $-9.7(-13.2$ to -6.3$)$ & 54.0 (51.5 to 56.5$)$ & 21.4 (16.7 to 26.1 ) \\
\hline Maine & 27,647 & 7.9 (4.6 to 11.3 ) & $-3.1(-4.8$ to -1.5$)$ & $3.4(1.0$ to 5.8$)$ & $-1.7(-4.0$ to 0.5$)$ \\
\hline District of Columbia & 50,971 & 7.0 (2.9 to 11.2$)$ & $0(-)$ & 89.6 (85.2 to 94.0$)$ & $0(-)$ \\
\hline Massachusetts & 239,342 & 6.8 (5.2 to 8.3 ) & $-4.6(-8.0$ to -1.1$)$ & 54.9 (51.2 to 58.5$)$ & 32.8 (28.2 to 37.3$)$ \\
\hline New Jersey & 446,439 & 6.7 (5.5 to 7.9 ) & $-8.5(-12.5$ to -4.4$)$ & 59.2 (56.7 to 61.7 ) & 41.4 (37.4 to 45.4$)$ \\
\hline Oregon & 302,998 & 4.4 (3.1 to 5.7$)$ & $-2.5(-3.5$ to -1.5$)$ & 80.5 (77.5 to 83.5$)$ & 5.5 (3.6 to 7.4$)$ \\
\hline California & $2,327,278$ & 4.0 (3.3 to 4.6$)$ & $-5.8(-6.8$ to -4.8$)$ & 79.1 (77.6 to 80.6$)$ & 17.4 (15.0 to 19.8$)$ \\
\hline Washington & 388,135 & 2.8 (2.2 to 3.5$)$ & $-1.1(-1.4$ to -0.8$)$ & 69.0 (66.2 to 71.8$)$ & $5.6(4.1$ to 7.1$)$ \\
\hline Maryland & 853,781 & 2.3 (0.9 to 3.8 ) & $-3.5(-6.1$ to -0.9$)$ & 76.9 (73.0 to 80.8$)$ & 11.3 (6.4 to 16.1 ) \\
\hline Hawaii & 181,088 & $1.3(-0.3$ to 3.0$)$ & $0(-)$ & 52.3 (42.1 to 62.4 ) & $0(-)$ \\
\hline
\end{tabular}

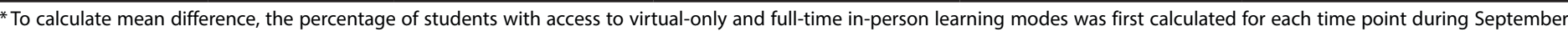

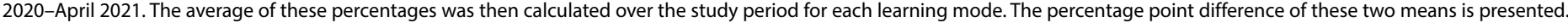

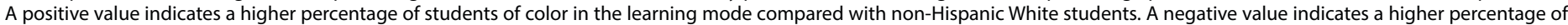
non-Hispanic White students in the learning mode compared with students of color.

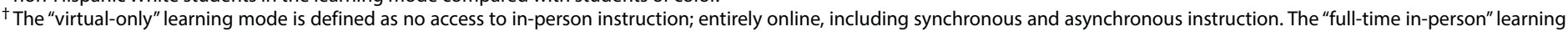
mode is defined as access to in-person instruction 5 days a week.

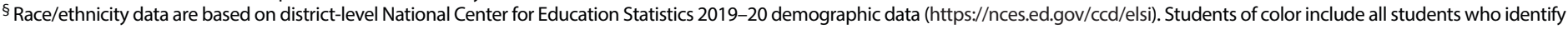

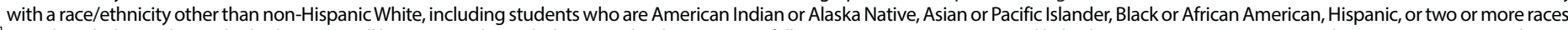

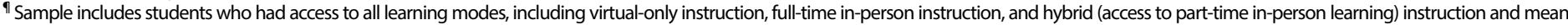

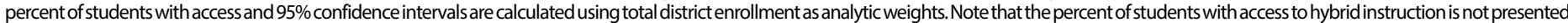
in this table to highlight a focus on virtual access and full-time in-person access. Thus, the columns presenting access to virtual-only and full-time in-person instruction might not sum to $100 \%$. 
FIGURE 2. Student access to learning modes, ${ }^{*}$ by grade level and race/ethnicity ${ }^{\dagger}$ — United States, September 2020-April $2021^{\S, \pi}$

A. Grades K-5

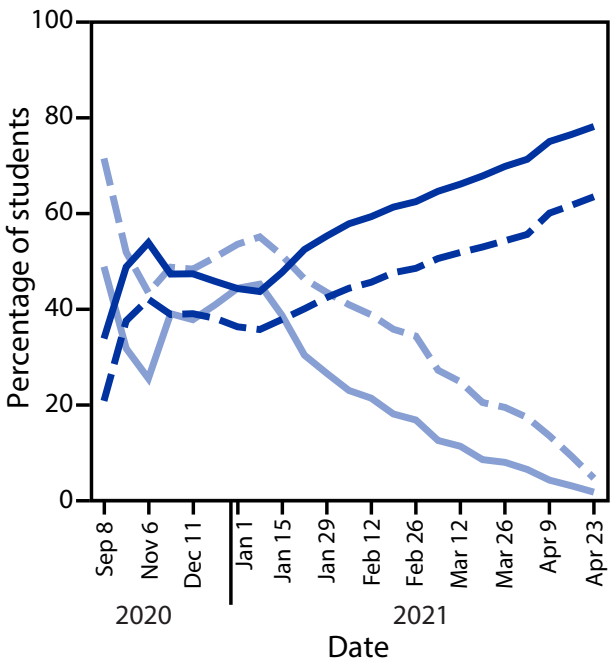

B. Grades 6-8

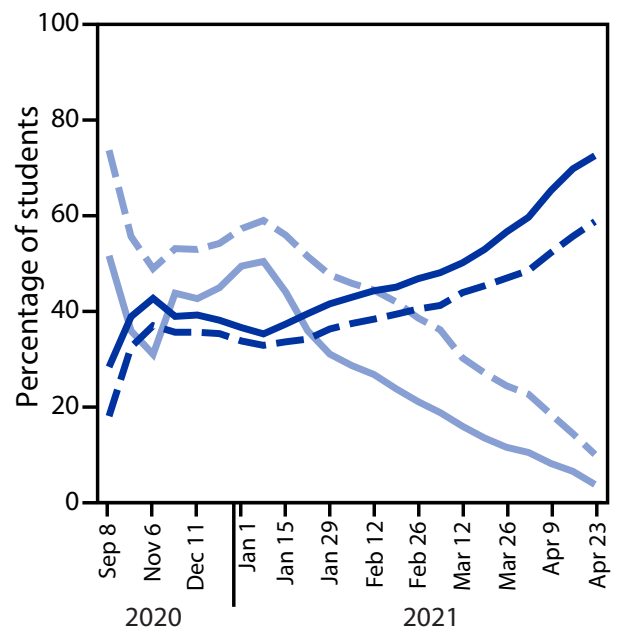

Date
C. Grades 9-12

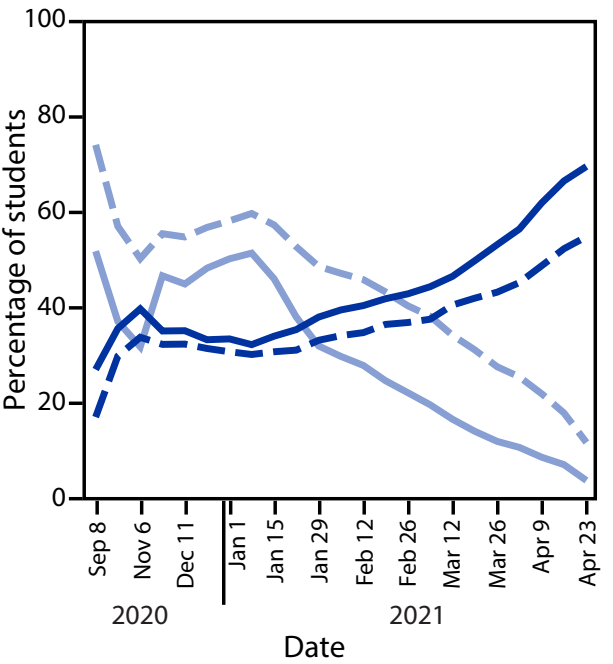

Full-time in-person access: non-Hispanic White students

- Full-time in-person access: students of color

- Virtual-only access: students of color

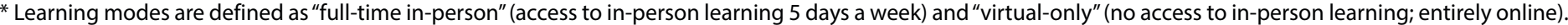

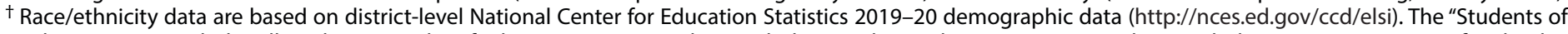

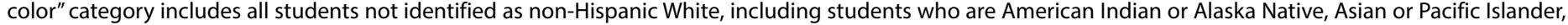
Black or African American, Hispanic, or two or more races.

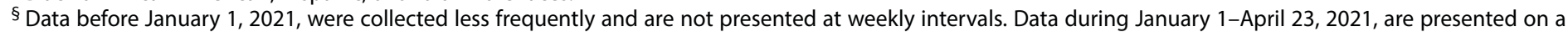
weekly basis. Date labels are condensed for readability.

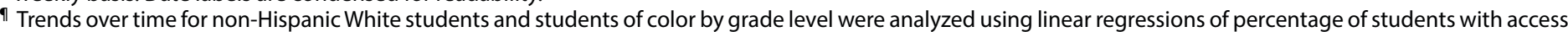

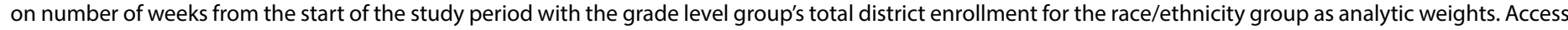

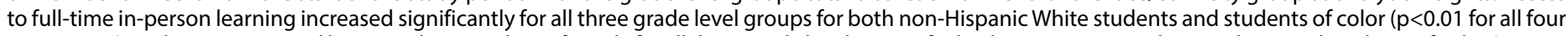

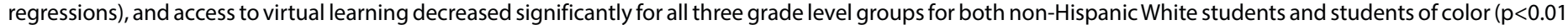
for all four regressions).

\section{Summary}

What is already known about this topic?

Reduced access to in-person learning is associated with poorer learning outcomes and adverse mental health and behavioral effects in children.

What is added by the report?

Although access to in-person, hybrid, and virtual learning modes varied throughout the school year, during January-April 2021, access to full-time in-person learning for non-Hispanic White students increased by 36.6 percentage points, 31.1 percentage points for non-Hispanic Black students, 22.0 percentage points for Hispanic students, and 26.6 percentage points for students of other race/ethnicities.

What are the implications for public health practice?

To increase equitable access to full-time in-person learning for the 2021-22 school year, school leaders should focus on providing safety-optimized in-person learning options across grade levels in all geographic areas. Vaccination and other efforts to reduce levels of community transmission should be intensified.

\section{References}

1. Woodworth JL, Raymond ME, Chirbas K, et al. Online charter school study 2015. Stanford, CA: Center for Research on Education Outcomes; 2015. Accessed May 26, 2021. https://credo.stanford.edu/publications/ online-charter-school-study

2. Verlenden JV, Pampati S, Rasberry CN, et al. Association of children's mode of school instruction with child and parent experiences and wellbeing during the COVID-19 pandemic-COVID experiences survey, United States, October 8-November 13, 2020. MMWR Morb Mortal Wkly Rep 2021;70:369-76. PMID:33735164 https://doi.org/10.15585/ mmwr.mm7011a1

3. Loades ME, Chatburn E, Higson-Sweeney N, et al. Rapid systematic review: the impact of social isolation and loneliness on the mental health of children and adolescents in the context of COVID-19 2020. J Am Acad Child Adolesc Psychiatry 2020;59:1218-1239.e3. PMID:32504808 https://doi.org/10.1016/j.jaac.2020.05.009

4. CDC. COVID-19: operational strategy for K-12 schools through phased prevention. Atlanta, GA: US Department of Health and Human Services, CDC; 2021. https://www.cdc.gov/coronavirus/2019-ncov/community/ schools-childcare/operation-strategy.html

5. Chen C. 2019-20 common core of data (ccd) universe files. Washington, DC: US Department of Education, National Center for Education Statistics; 2021. Accessed May 4, 2021. https://nces.ed.gov/pubsearch/ pubsinfo.asp?pubid $=2021150$ 
6. Karaca-Mandic P, Georgiou A, Sen S. Assessment of COVID-19 hospitalizations by race/ethnicity in 12 states. JAMA Intern Med 2021;181:131-4. PMID:32804192 https://doi.org/10.1001/jamainternmed.2020.3857

7. National Center for Education Statistics; Institute of Education Sciences. National survey finds three-quarters of public schools open for full-time in-person or hybrid instruction [Press release]. Washington, DC: US Department of Education, National Center for Education Statistics; 2021. https://nces.ed.gov/nationsreportcard/subject/about/pdf/2021_school_ survey_press_release.pdf

8. Gold JAW, Rossen LM, Ahmad FB, et al. Race, ethnicity, and age trends in persons who died from COVID-19-United States, May-August 2020. MMWR Morb Mortal Wkly Rep 2020;69:1517-21. PMID:33090984 https://doi.org/10.15585/mmwr.mm6942e1
9. Gilbert LK, Strine TW, Szucs LE, et al. Racial and ethnic differences in parental attitudes and concerns about school reopening during the COVID-19 pandemic - United States, July 2020. MMWR Morb Mortal Wkly Rep 2020;69:1848-52. PMID:33301437 https://doi. org/10.15585/mmwr.mm6949a2

10. Falk A, Benda A, Falk P, Steffen S, Wallace Z, Høeg TB. COVID-19 cases and transmission in $17 \mathrm{~K}-12$ schools-Wood County, Wisconsin, August 31-November 29, 2020. MMWR Morb Mortal Wkly Rep 2021;70:136-40. PMID:33507890 https://doi.org/10.15585/mmwr. $\mathrm{mm} 7004 \mathrm{e} 3$ 